\title{
Consumo da merenda escolar por alunos de duas escolas públicas das regióes nordeste e sudeste do Brasil.
}

\section{Consumption of school lunches for students from two public schools in the northeastern and southeastern Brazil.}

\section{Resumo}

O Brasil tem vivenciado uma transição nutricional muito grande, levando ao surgimento de sobrepeso e obesidade nas diferentes classes sociais. Dados da coordenação da Política Nacional de Alimentação e Nutrição (PNAN) informam que, ao mesmo tempo em que se observa o aumento de calorias per capita e da participação de alimentos de origem animal na mesa do brasileiro, constata-se a substituição de cereais, frutas, verduras e legumes por gorduras em geral e açúcares. Neste estudo investigamos os alimentos consumidos na merenda escolar pelos alunos do Ensino Fundamental de duas escolas públicas situadas na regiẫo nordeste e sudeste do Brasil. Utilizamos um questionário denominado de Agenda Alimentar que foi preenchida por eles com os alimentos consumidos enquanto estavam na escola durante uma semana. Também foram coletados dados de alguns alunos, através de uma entrevista semi estruturada, de modo aleatório. Os resultados mostraram que os alunos pesquisados da região nordeste consomem os alimentos da merenda e não fazem seleção entre os mesmos, enquanto os alunos selecionados da região sudeste fazem escolhas dentre os alimentos oferecidos.

Palavras-chave: alunos, merenda escolar, atividades diferenciadas.

\section{Abstract}

Brazil is undergoing to a great nutrition transition, leading to the emergence of overweight and obesity in different social classes. Coordinated data from the National Food and Nutrition (PNAN) showed that, while it has been an increasing of calories per capita and a growing of food from animal origin in the Brazilian nutrition, there is a replacement of cereals, fruits and vegetables by fats and sugars, in general. In this study we investigated the food consumed in school lunches by elementary school students from two public schools located in the northeastern and southeastern of Brazil. We used a questionnaire called Agenda alimentar which was completed with the name of food they consumed in the school during one week. In addition, data were collected through a semistructured interview to some students randomly. The results showed that students from the Northeast school consume snack foods and do not select among them, while the students from the Southeast make choices among the foods offered.

Keywords: students, school lunches, differentiated activities. 


\section{INTRODUÇÃO}

A alimentação é o combustível para nossa vida, uma vez que nos fornece subsídios para a realização de nossas tarefas diárias. Se não nos alimentarmos não teremos força ou disposição para a realização das nossas atividades, comprometendo o desempenho das funçóes vitais do organismo. É preciso que nos alimentemos corretamente, fornecendo ao organismo os nutrientes necessários para seu funcionamento, sem carências ou exageros (Junqueira, 2000, Ochsennhofer et al, 2006). A alimentação e a nutriçáo são fundamentais para o desenvolvimento do indivíduo e devem estar contextualizadas nas açóes integradas para a promoção da saúde.

O Brasil tem vivenciado uma transição nutricional, típico dos países em desenvolvimento, muito grande, levando ao surgimento de sobrepeso e obesidade nas diferentes classes sociais. Dados da coordenação da Política Nacional de Alimentaçáo e Nutrição (PNAN) informam que, ao mesmo tempo em que se observa o aumento de calorias per capita e da participação de alimentos de origem animal na mesa do brasileiro, constata-se a substituição de cereais, frutas, verduras e legumes por gorduras em geral e açúcares (De Lavor, 2007).

A "transição nutricional” é caracterizada pela substituição do consumo de alimentos tradicionais, in natura, por alimentos altamente processados, produzidos por grandes indústrias de alimentos, boa parte deles de alta densidade energética e pobres em nutrientes, ou seja, maior quantidade, menor qualidade. Estima-se que o consumo de frutas e hortaliças no Brasil corresponda a menos da metade das recomendaçóes nutricionais, sendo ainda mais deficiente entre as famílias de baixa renda (Levy-Costa et al, 2005, Felice et al, 2007). Hábitos alimentares adequados proporcionam ao organismo humano condiçôes para uma vida saudável, acrescentando anos com saúde e disposição para os indivíduos que se propóem a ter uma dieta equilibrada e pautada na moderação.

$\mathrm{Na}$ adolescência surgem alguns conflitos referentes à alimentação, devido a persistência em ingerir alimentos inadequados a saúde. O consumo de alimentos está associado aos hábitos alimentares da família, a influência da mídia, dos amigos, além dos apelos do fast food e do junk food (Pipitone et al, 2003), à medida que a criança cresce, até o momento em que ela própria escolherá os alimentos que farão parte do seu cardápio cotidiano (Zancul \& Dutra de Oliveira, 2007).

A pirâmide construída a partir da freqüência de veiculação de alimentos na TV difere substancialmente da pirâmide considerada ideal, pois consumir um mesmo tipo de alimento pode oferecer ao organismo nutriente em excesso, e conseqüentemente, carência de outros podendo causar várias doenças e a carência de outros, também importantes. A recomendaçáo de nutrientes pode variar entre as populaçôes e, por isso, houve a necessidade de ela ser adaptada para a população brasileira visando, principalmente, atingir as recomendaçôes dos macronutrientes que são de $50 \mathrm{a}$ $60 \%$ do valor de calorias totais ingeridas em um dia (VCT) de carboidratos, 10 a 15\% do VCT de proteínas e 20 a 30\% do VCT em gorduras.

A mídia no que se refere às propagandas apresentadas na televisão, jornais e revistas, vem contribuindo e estimulando o consumo de alimentos sem valor nutricional, além de utilizar-se de estratégias de marketing para captarem as crianças como potenciais influenciadores nas compras dos pais. Além dessa freqüência publicitária para o consumo desses alimentos inadequados nos meios de comunicação social, também se faz presente o sedentarismo, principais responsáveis pelo número crescente da obesidade no mundo.

Considerada uma epidemia, a obesidade vem crescendo assustadoramente nos últimos anos, e vem acometendo cada vez mais as crianças. Infelizmente, o que temos visto é um quadro extremamente preocupante, pois elas estão ingerindo alimentos altamente calóricos e pobres em nutrientes, como doces, refrigerantes, fast foods, salgadinhos, etc. Existiam no Brasil em 1989, cerca de um milhão e meio de crianças obesas, sendo que a prevalência era um pouco maior entre meninas que entre meninos, nas regióes Sul e Sudeste (Taddei, 1995). No entanto, dados do inquérito nacional de 1996 (que só incluiu crianças menores de 5 anos), mostraram que a obesidade na região Nordeste havia aumentado (Taddei et al., 1998), provavelmente em decorrência do tipo de alimentação.

Considerando que o tempo que a criança passa na escola é maior, muitas vezes, do que aquele que ela passa em casa, a instituição de ensino tem uma influência cada vez mais abrangente na alimentação de seus alunos, seja por influência de professores, colegas ou outros meios de informação. Sendo assim, ela pode desenvolver estratégias diferenciadas que despertem a atenção dos alunos para a importância da escolha alimentar. Além da influência da escola é preciso também destacar o papel fundamental dos pais nesse processo. Crianças que desde pequenas no convívio familiar observam o comportamento dos pais em relação ao consumo de frutas e verduras, sucos naturais, água e a prática de atividades físicas terão muito mais facilidade de desenvolver um estilo de vida adequado (Viuniski, 2005).

Alguns problemas como déficit de atenção, falta de concentraçáo, hiperatividade, deficiência de memória, entre outros, podem estar associados aos erros alimentares (Salgado, 2007). Para evitar estes problemas, os pais poderão monitorar o tempo que as crianças passam na frente da TV, definir o que a criança deve consumir como lanche escolar, além de incentivar a prática de atividade física, entre outras atitudes, sempre com o objetivo de orientar escolhas mais saudáveis. Cabe a família levar à criança a preferir alimentos saudáveis, 
indispensáveis ao seu desenvolvimento, evitando uma dieta desbalanceada e nociva à saúde. Programas de promoção de saúde e nutrição nas escolas podem melhorar a aprendizagem e os resultados educacionais das crianças, bem como a educação de qualidade pode conduzir aos melhores resultados de saúde e nutrição (Unicef, 2000). Assim, a sala de aula torna-se um espaço social privilegiado para contextualizar os conteúdos a partir da interação entre os saberes curriculares e os demais saberes da sociedade, proporcionando a cada aluno a possibilidade de construir o conhecimento, vivenciando e desenvolvendo as suas competências e habilidades individuais (Torres, 2003).

As questóes acerca da alimentação e do meio ambiente perpassam todas as áreas do conhecimento e precisam ser discutidas de forma integral, por meio da articulação entre as diversas disciplinas curriculares, a fim de estimular a integralidade do ensino, a interdisciplinaridade e a promoção da educaçáo para a saúde. No mês de maio, a escola comemora a semana da alimentação e, portanto aproveitando este momento durante as aulas de Ciências, investigamos o consumo de merenda escolar pelos alunos das séries em que atuamos.

Nesta perspectiva, este trabalho retrata o consumo da merenda escolar dos alunos do Ensino Fundamental, durante uma semana em escolas situadas em dois estados do Brasil, com seus costumes e cultura diferenciados, daí a curiosidade de investigar os hábitos alimentares, pois o meio escolar constitui uma excelente oportunidade para incentivar uma alimentação saudável.

\section{CAMINHO METODOLÓGICO}

\section{Local e sujeitos do estudo:}

Os alunos envolvidos no estudo estavam distribuídos nos $5^{\circ}, 6^{\circ} 7^{\circ}$ e $8^{\circ}$ anos do Ensino Fundamental e freqüentavam escolas públicas situadas em 2 regióes geográficas do Brasil: 103 alunos de uma escola, situada na zona oeste do município do Rio de Janeiro/RJ e 62 alunos de uma escola, situada na regiâo central do município de Caxias/MA. Estas escolas foram escolhidas, pois em épocas distintas foram locais de trabalho da autora. O trabalho desenvolvido no decorrer das aulas de Ciências durante a Semana de Alimentação Escolar que acontece na terceira semana do mês de maio fazia parte das diferentes atividades planejadas para esta semana com enfoque de despertar o interesse dos alunos sobre o tema. As Unidades Escolares estavam cientes das atividades porque faziam parte do Projeto Político Pedagógico.

\section{Instrumentos de coleta de dados:}

Os alunos preencheram dois questionários: um sobre o perfil socioeconômico (PSE) (Figura 1) e outro deno- minado de Agenda Alimentar. Após o preenchimento da Agenda, alguns alunos, que participaram da atividade, foram escolhidos aleatoriamente e responderam a uma entrevista semi estruturada.

\begin{tabular}{|c|}
\hline $\begin{array}{l}\text { 1 - Instituição: } \\
\text { 2- Idade: }\end{array}$ \\
\hline
\end{tabular}

Figura 1: Instrumentos de coleta de dados: Perfil Socioeconômico (PSE).

Os dados referentes ao PSE dos estudantes foram obtidos por meio de um questionário simples, composto de perguntas objetivas sobre a escolaridade dos pais, a renda familiar, idade e gênero. O questionário foi respondido anonimamente pelos alunos entre os dias 07/06 a 11/06/2010, simultaneamente nas escolas em estudo.

Para identificarmos a freqüência de consumo e os itens da merenda consumidos pelos alunos foi utilizado o questionário denominado de Agenda Alimentar (AGA), cuja metodologia foi utilizada conforme Alves-Oliveira (2008). A AGA foi entregue aos alunos no início de uma semana e recolhida no final da mesma. Na AGA, havia espaço distribuído com os dias da semana, de segunda à sexta feira para que o aluno assinalasse se consumia ou não a merenda escolar a cada dia, e, em caso afirmativo, os itens alimentares consumidos. $\mathrm{O}$ aluno deveria registrar também os alimentos consumidos que não faziam parte da merenda escolar.

A única dúvida dos alunos quanto ao preenchimento, durante a padronização, dizia respeito à inclusão de todos os alimentos consumidos ao longo do dia ou somente aqueles consumidos no período de permanência na escola (sendo este último o nosso objetivo). Os alunos foram instruídos quanto à maneira correta de preenchimento da AGA e sobre a data de devolução. Os instrumentos foram recolhidos no último dia do período determinado para seu preenchimento.

A entrevista incluía cinco questóes, sendo quatro objetivas. Em todas as cinco questóes, as respostas deveriam ser justificadas. As questóes eram relacionadas à freqüência de consumo da merenda escolar, às sugestôes de mudança na sua composição, aos motivos que os fariam merendar com maior ou menor freqüência e à influência dos responsáveis sobre suas decisôes de consumir ou não a merenda escolar.

Os alunos que responderam à entrevista foram selecionados ao acaso, embora tivéssemos o cuidado de recolher dados 
de alunos que pertenciam a todas as séries envolvidas do turno matutino e se consumiam ou não a merenda, apenas no Maranhão, pois outras atividades desenvolvidas na escola do Rio de Janeiro impediram a aplicação da mesma. As questóes da entrevista foram respondidas pelos alunos após o recolhimento da AGA. A distribuição do número de alunos participantes por ano de escolaridade, por município e por instrumento de coleta de dados respondidos encontra-se no Quadro 1.

\begin{tabular}{|c|c|c|c|c|c|}
\hline Ano de escolaridade & Caxias (MA) $\mathbf{n}$ & Rio de Janeiro (RJ) $\mathbf{n}$ & AGA $^{*}$ & PSE $^{*}$ & Entrevistas semi-estruturadas \\
\hline $5^{\circ}$ ano & 23 & - & 23 & 10 & 10 \\
\hline $6^{\circ}$ ano & 16 & 65 & 81 & 14 & 14 \\
\hline $7^{\circ}$ ano & 12 & 12 & 24 & 9 & 9 \\
\hline $8^{\circ}$ ano & 11 & 26 & 37 & 10 & 10 \\
\hline
\end{tabular}

Quadro 1: Distribuição de alunos por ano de escolaridade que preencheram os instrumentos de coleta:

a AGA $(n=165)$, o PSE $(n=43)$ e as Entrevistas $(n=43)$ nas duas escolas de estudo.

\section{Caracterizaçáo do Consumo de Merenda Escolar}

O estudo teve como fonte de dados o cardápio referente a uma semana da alimentação escolar planejada. As merendas eram oferecidas nos refeitórios das escolas em horários diferenciados. Na escola do Rio de Janeiro, a merenda era servida no intervalo de 10:30h às 10:50h e na escola de Caxias no intervalo de 9:30h às 9:50h onde os alunos sentavam em grupos, no momento em que a merenda era servida.

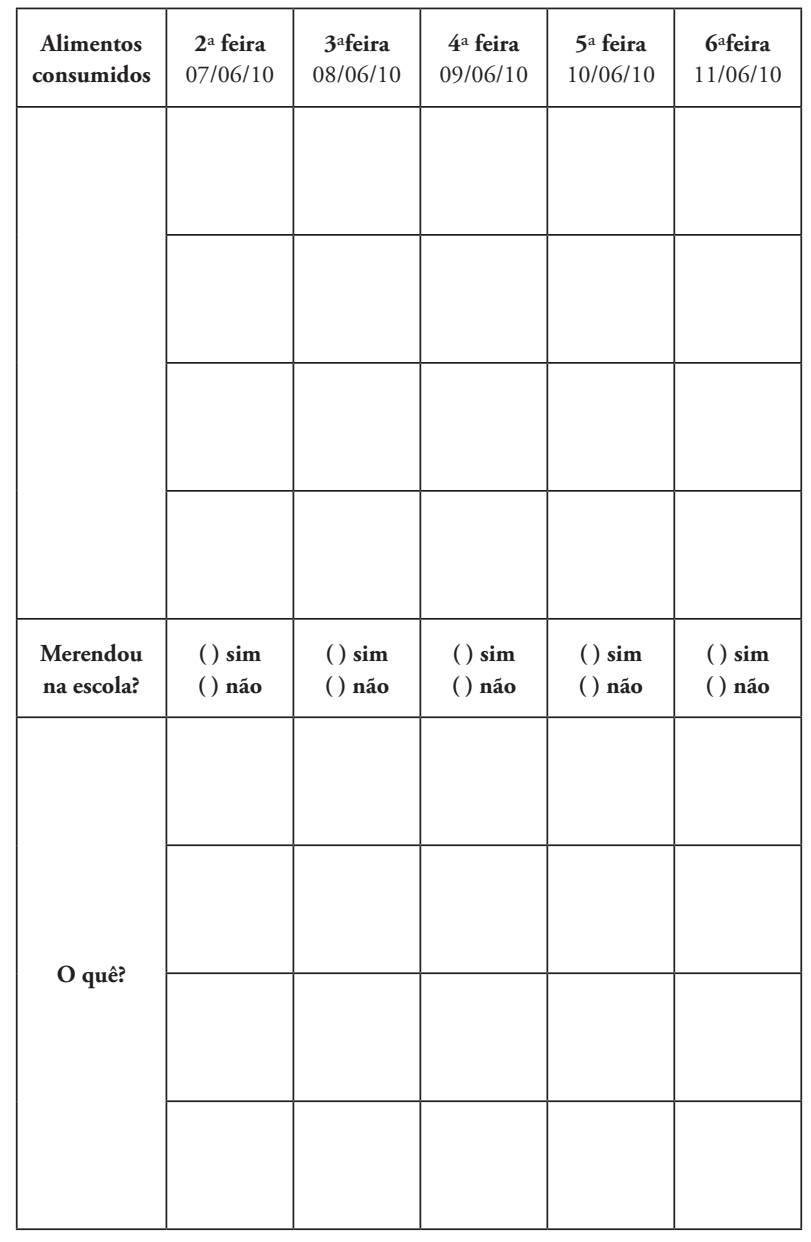

\section{Motivaçóes para o consumo de merenda escolar}

Os instrumentos de coleta de dados (AGA e entrevistas semi-estruturadas) (Figura 2) adotados por Alves-Oliveira (2008) foram utilizados para investigar os motivos da adesão ou não ao consumo da merenda escolar, pelos alunos que participaram do estudo.

\section{Entrevistas Semi Estruturadas}

\begin{tabular}{l|l|} 
Ministério da Saúde \\
FIOCRUZ \\
Fundaçáo Oswaldo Cruz \\
Instituto Oswaldo Cruz \\
Pós-Graduação em Ensino em Biociências e Saúde
\end{tabular}

Escola: Turma: Série: Idade: Data:

Agradeço a sua participaçáo na pesquisa. É importante saber a sua opiniáo a respeito da merenda escolar

1 - Você merenda na escola?

Sim ( ) Quantas vezes por semana mais ou menos? Porquê?

Não ( ) Por quê?

2 - Você gosta da merenda da escola?

Sim ( ) Por quê?

Não ( ) Por quê?

3 - Você mudaria a composição da merenda da escola?

Não ( )

Sim ( ) O que você mudaria?

4- O que faria você merendar mais vezes na escola?

5- O Horário em que a merenda é servida é satisfatório? Sim ( ) Não ( )

6 - Seus responsáveis opinam quanto a você merendar ou não na escola? Sim ( ) Por quê?

Não ( ) Por quê? 


\section{RESULTADOS E DISCUSSÃO}

Os alunos que participaram do estudo $(\mathrm{n}=165)$ são adolescentes de 10 a 19 anos, matriculados na rede pública de ensino, no turno diurno e pertenciam as famílias de baixa renda, uma vez que quase 130 alunos possuíam renda familiar de até 3 salários mínimos nas duas escolas

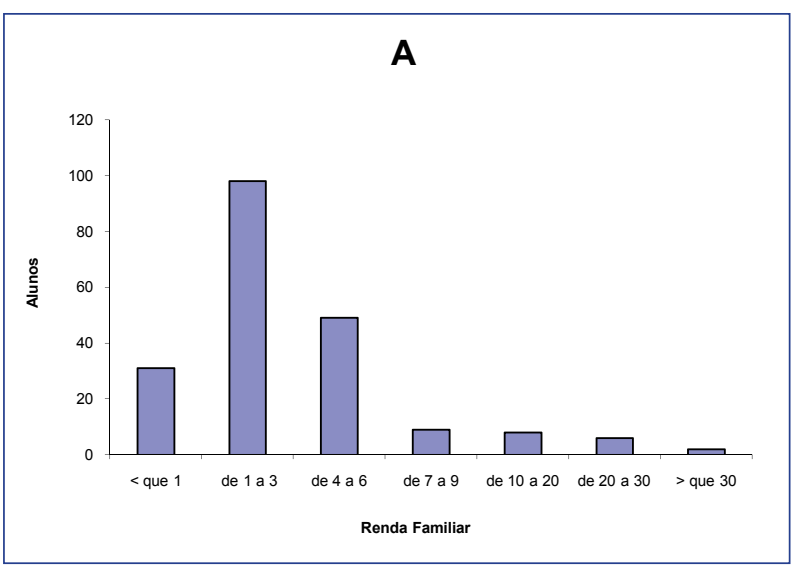

Figura 3: Distribuição dos alunos quanto à renda familiar estratificada (A) em salários mínimos e a escolaridade dos pais (B)

A utilização da AGA permitiu identificar o número de alunos que consumiam a merenda escolar a cada dia e a freqüência com que o faziam. Os dados revelaram que dentre os alunos investigados, 56 alunos da escola do Rio de Janeiro nấo merendam e que 25 alunos de Caxias/MA também procederam desta forma. Observamos que o número de alunos que consumiu a merenda escolar, tanto do município de Caxias/MA quanto do Rio de Janeiro/RJ, durante os cinco dias da semana (Figura 4), é pequeno. O baixo consumo de merenda não parece estar relacionado diretamente aos alimentos oferecidos.

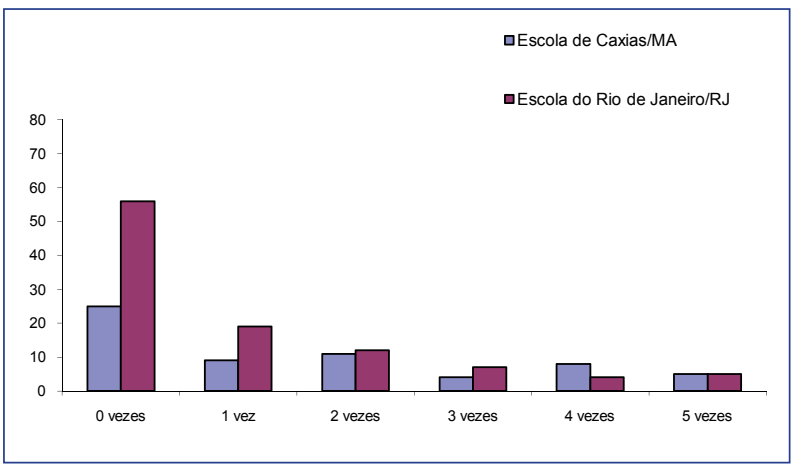

Figura 4: Comparação entre o consumo da merenda escolar oferecida por número de alunos nas duas escolas de estudo de acordo com o número de vezes com o cardápio oferecido. investigadas (Figura 3A). Em relação à escolaridade dos pais nem todos os entrevistados responderam e constatamos que 25 máes e 20 pais possuíam apenas o Ensino Médio e um número de 90 mães e pais possuíam apenas o Ensino Fundamental completo. De qualquer modo a populaçáo observada nas duas escolas localizadas em diferentes regióes do Brasil é muito homogênea (Figura 3B).

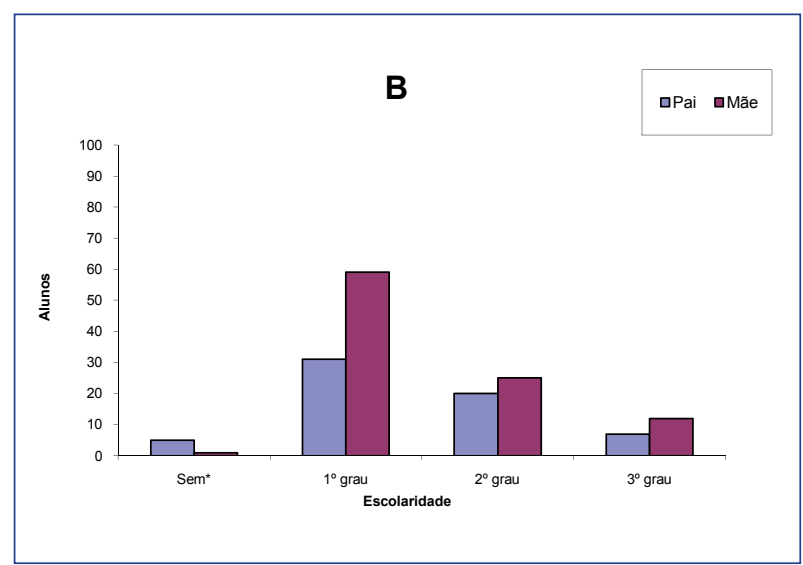

Embora exista uma carência de estudos sobre o consumo de merenda escolar no estado do Maranháo, um amplo estudo ao nível nacional foi realizado por Sturion $e$ colaboradores em 2005. Os autores investigaram o nível de adesão de 2.678 alunos, com idades entre 7 a 11 anos ao Programa de Alimentação Escolar de 10 municípios brasileiros, sendo dois de cada região geográfica. Os dados mostraram que, em média, 46\% dos alunos consomem diariamente a alimentaçáo oferecida na escola, enquanto apenas $17 \%$ não participam do Programa. Os dados, no entanto, são extremamente heterogêneos, uma vez que a adesão (indicada por alunos que merendam pelo menos uma vez por semana) varia de 31,3\% até 99,3\% dos alunos. Além disso, mesmo entre duas escolas de mesmo porte de um mesmo município, a adesão pode variar de $31,3 \%$ até $72,8 \%$ dos alunos. Essa heterogeneidade possivelmente indica a importância de fatores locais na determinação do consumo de merenda escolar.

Estudos anteriores identificaram uma associação negativa entre a faixa etária e o consumo de merenda para o conjunto dos alunos por eles estudados (Sturion et al, 2005). Os dados obtidos na escola do Rio de Janeiro/RJ sugerem que na medida em que ocorre a progressão escolar, o aluno se distancia do consumo da merenda (Figura 5), corroborando com estudos anteriores da Pesquisa Nacional Saúde e Nutrição (PNSN, 1989) de Sturion e colaboradores (2005), e Alves-Oliveira (2008). O mesmo não é observado na maioria das turmas da escola de Caxias/MA. 


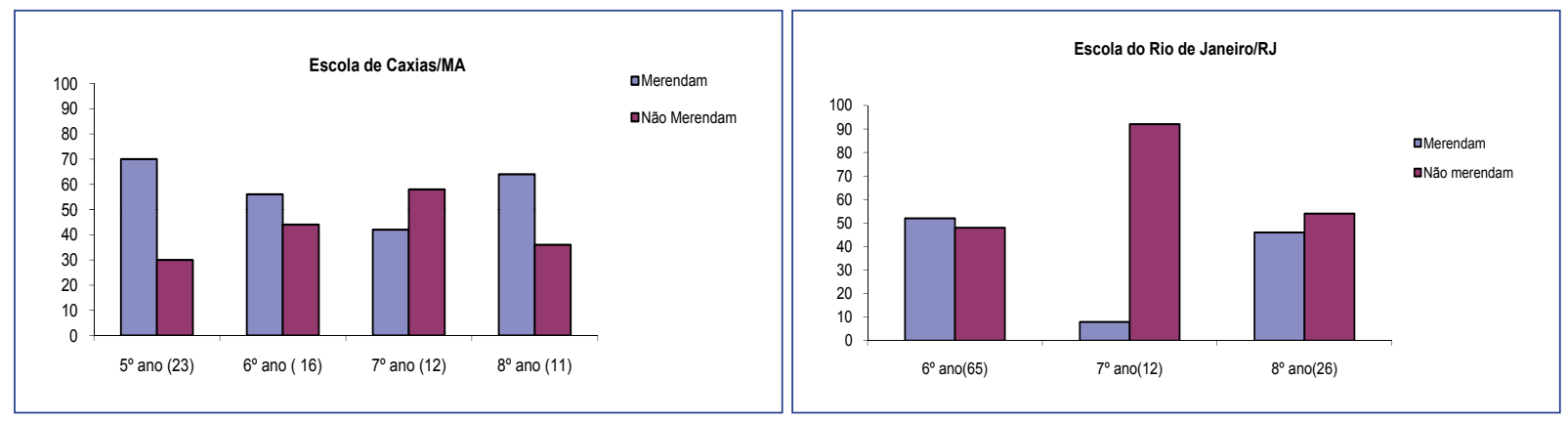

Figura 5: Consumo da merenda escolar das escolas em estudo, de acordo com o ano de escolaridade do Ensino Fundamental.

Nosso estudo trata de consumo de merenda escolar em duas regiōes (Sudeste e Nordeste do Brasil) com diferenças econômicas e de desenvolvimento social extremas. A aceitação da merenda em todas as séries da escola de Caxias/MA pode ser justificada tomando como base estudo de Flavio e colaboradores (2004), onde relata que no Brasil um número, significativo de crianças vai à escola motivada pelo oferecimento da alimentação escolar, uma vez que chegam à escola em jejum ou se alimentaram de maneira inadequada em suas residências, devido às baixas condiçóes socioeconômicas da família. Segundo Abreu (1995), a alimentação fornecida pelas escolas é para muitos alunos sua única refeição diária.

De acordo com Spinelli \& Canesqui (2004), a oferta da alimentação escolar tem valor positivo para os alunos devido à existência de fome entre eles, conforme relatado pelos próprios alunos do estudo dos autores: "porque têm muitas crianças que vão para a escola com fome elas não têm nada pra comer em casa"; "muitas desmaiam de fome, porque eu quase desmaiei"; "quando a merenda acaba nós ficamos fracos porque tem dia que quase ninguém toma café para ir para escola”. Estes relatos são descritos por milhóes de crianças brasileiras onde a merenda não é só a principal refeição do dia, mas a única - e ela só cobre 15\% das necessidades diárias do aluno (Flavio et al.,2004),

Analisando os itens da merenda consumidos pelos alunos (Figura 6), verificou-se uma diferença nos cardápios das escolas em estudo, dentre os alimentos de origem animal observou-se a ausência de carne vermelha e do feijão na merenda dos alunos da escola de Caxias/MA. Foi observado que 65 dos 103 alunos da escola do Rio de Janeiro/RJ fazem uso do feijão em sua alimentação. Abreu (2005) em seus estudos relata que o feijão é um dos mais importantes componentes da dieta alimentar do brasileiro, pois possui bom conteúdo de carboidratos, vitaminas (principalmente as do complexo B), minerais (ferro, cálcio, magnésio, zinco), fibras e compostos fenólicos com ação antioxidante que podem reduzir a incidência de doenças. Já a concentração de proteína no grão do arroz é, em geral, próxima de $7 \%$ com pequenas variaçóes. $\mathrm{O}$ arroz possui um perfil de aminoácidos essenciais mais adequados em termos nutricionais que o de outros cereais como o milho comum e o trigo.

Nossos resultados (Figura 6) mostraram um consumo diferenciado de arroz e feijão, isoladamente nas escolas em estudo. Apenas na escola do Rio de Janeiro o feijão e arroz eram itens permanentes na merenda sendo feijão o item mais consumido enquanto no Maranhão o feijão não fazia parte do cardápio. Um tipo de fibra que é consumida do feijão ajuda a reduzir o risco de doenças como diabetes, câncer de cólon, doenças cardiovasculares, além de contribuir para o aumento do bolo fecal, para o melhor funcionamento do intestino e diminuição do tempo do trânsito intestinal (Embrapa Arroz e Feijão, 2006).
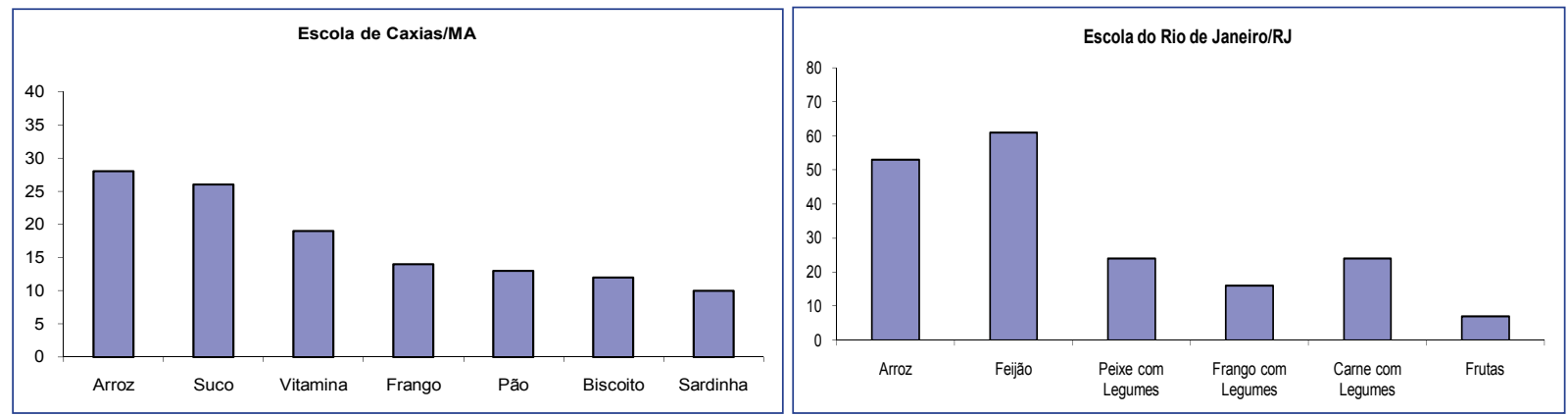

Figura 6: Itens da merenda versus Números de alunos que consumiram:

(Escola de Caxias/MA e Escola do Rio de Janeiro/RJ) alunos das quatro séries do ensino fundamental em uma mesma semana. 


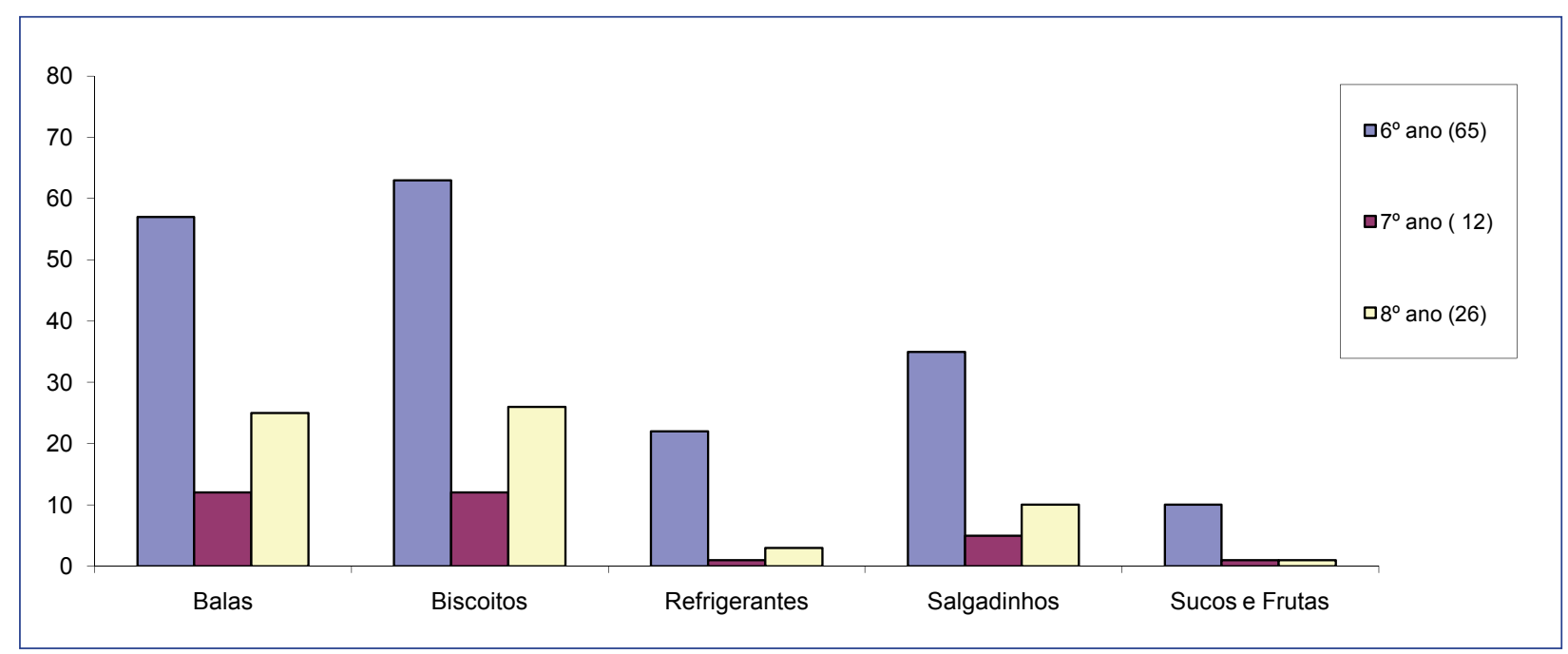

Figura 7: Consumo de alimentos variados pelos alunos dos diferentes anos do Ensino Fundamental da escola do Rio de Janeiro/RJ.

Do total de alunos da escola de Caxias/MA, 45 alunos consomem as frutas sob a forma de Sucos e Vitaminas (palavra usada pela população para designar a mistura de leite, cereais e frutas). Os alunos consomem a mistura oferecida pela escola. $\mathrm{Na}$ escola do Rio de Janeiro/RJ não existe esta mistura, pois as frutas são oferecidas naturalmente. Do total de 103 alunos entrevistados 31 deles afirmaram que consumem as frutas oferecidas pela escola, uma vez que estão presentes no cardápio. A fruta é oferecida como sobremesa e o aluno escolhe se come ou náo.

Este resultado corrobora com os dados de Silva e Neutzling (2007), que apontaram um baixo consumo de frutas e legumes entre os adolescentes escolares de Pelotas/ RS mostrando uma freqüência de consumo diário de frutas de $24,8 \%$ e de legumes $20,1 \%$. O baixo consumo de frutas e verduras apresentado neste estudo é também semelhante aos resultados de Toral e colaboradores (2006) que avaliaram o comportamento alimentar de adolescentes em relação ao consumo de frutas e verduras e concluíram que os participantes do seu estudo, alunos voluntários na faixa etária de 10 a 19 anos, não reconhecem suas práticas alimentares inadequadas, o que representa um obstáculo aos programas de educação nutricional. Esses resultados possibilitam a classificação dos adolescentes como um grupo de risco, que exige atenção especial para a promoção de hábitos alimentares saudáveis e garantia de qualidade de vida futura.

Algumas respostas das AGAs foram identificadas apenas na escola do Rio de Janeiro/RJ no que se referem aos demais alimentos consumidos pelos alunos dentro da escola (Figura 7). Estes alimentos estão inseridos no grupo dos doces e guloseimas, destacando o consumo de balas, biscoitos e salgadinhos em todos os anos escolares, com freqüência de consumo, pelo menos 3 vezes por semana como os itens mais consumidos. Entretanto, os sucos e as frutas tiveram consumo mínimo, corroborando com o Alves-Oli- veira, (2008). O consumo elevado de açúcares e doces na alimentação dos adolescentes é um problema relatado na literatura (Toral; Slater; Silva, 2007, Coelho, 2008; Cavalcanti, 2009).

Outro estudo reforça tais resultados como o publicado pelo Instituto Nacional de Saúde dos Estados Unidos, onde examinaram o consumo de calorias na população infantojuvenil através da análise da dieta de 14 mil crianças e adolescentes de 2 a 18 anos. As conclusóes foram preocupantes: $40 \%$ da energia consumida eram provenientes das chamadas "calorias vazias", encontradas em alimentos energéticos e pouco nutritivos, como balas e refrigerantes, essas "calorias vazias" são uma das principais responsáveis pela obesidade, contribuindo para quadros nos quais o individuo está acima do peso, mas com déficit nutricional (Costa, 2010).

O esclarecimento sobre a importância dos nutrientes em sala de aula com atividades diferenciadas pode despertar a atenção de alunos em relação aos seus hábitos alimentares e na quebra de alguns tabus, contribuindo na aceitação e adesão da merenda escolar. Outra opção seria propor às prefeituras uma pesquisa em relaçáo aos alimentos que os adolescentes gostariam de consumir nas refeiçóes oferecidas pela escola com a possibilidade de implementá-los.

A alimentação no mundo contemporâneo é uma questáo complexa e como tal requer açôes em diferentes níveis a fim de solucionar ou minimizar os impactos já causados ao ambiente e à saúde da população. Os profissionais da saúde e da educação, por sua natural ação multiplicadora, em muito podem contribuir realizando atividades de sensibilização e de informação sobre as questôes envolvidas com o consumo alimentar.

Pequenas mudanças nos hábitos alimentares do cotidiano dos jovens e de suas famílias podem contribuir para uma alimentação mais saudável, que valorize mais o alimento in natura e que reduza ao mínimo a presença de 
alimentos industrializados. Esta atitude atrelada à atividade física pode intervir na qualidade de vida do indivíduo.

A escola pode contribuir no sentido de estimular a alimentação saudável. Deste modo, a escola cumpre parte de sua função social na promoção da qualidade de vida de modo a efetivar um processo de alimentação saudável não apenas no seu interior, mas também nas relaçóes que o aluno estabelece entre os seus.

\section{CONCLUSÓES}

Nesse estudo percebemos por meio dos resultados os pontos que atrelam o consumo de merenda escolar $x$ alunos e constatamos que:

- $\quad$ O número de alunos que consomem a merenda ao longo da semana (5 dias) é inferior a $20 \%$ do total de alunos submetidos a pesquisa, justificado pelos alunos por "não gostarem de alguns itens da merenda" onde os mesmos afirmam uma falta de variedade, de acordo com as respostas das entrevistas.

- $\quad \mathrm{Na}$ escola do Rio de Janeiro/RJ à medida que ocorre a progressão escolar diminuem o consumo da merenda, seja por "vergonha dos colegas"; "modismo", ter o "dinheiro para compra de lanches" e outros fatores observados que venham influenciar na aversão à merenda escolar.

- Na escola de Caxias/MA, embora exista uma carência de alimentos como carne vermelha e feijão, o "biscoito" (alimento industrializado) esta incluído na merenda em um dos dias da semana, porém seu consumo pelos alunos não é maior do que o dos outros alimentos, exceto a sardinha.

- Observamos uma diferença entre as refeições oferecidas nas duas escolas em relação à qualidade e a quantidade de alimentos. Na escola do Rio de Janeiro/RJ as refeiçóes são completas durante toda a semana, enquanto, na escola de Caxias/MA só é oferecida as refeiçôes em dois dias da semana, nos demais dias são oferecidos lanches.

- Percebemos que os alunos se envolveram nas diferentes atividades sobre a Semana da Alimentação e ficaram surpresos com os resultados apresentados.

É necessário que as prefeituras atentem para o fato de inserir na merenda, alimentos indispensáveis para o desenvolvimento da criança e que os professores possam também desenvolver estratégias diferenciadas que viabilizem mudança nos hábitos alimentares.

\section{REFERÊNCIAS BIBLIOGRÁFICAS}

1. ABREU, M. Alimentação escolar: combate à desnutrição e ao fracasso escolar ou direito da criança e ato pedagógico. In: Brasil, Ministério da Educação e do Desporto, SEDIA/INEP. Em aberto: merenda escolar. 67:5-20. 2005.

2. ALVES - OLIVEIRA, M. F., "Construindo o conhecimento sobre nutrientes no Ensino Fundamental: elaboração e a avaliação de atividades investigativas e sua influência nos hábitos alimentares dos alunos do Rio de Janeiro (Brasil)". Tese de doutorado. Instituto Oswaldo Cruz. Fundação Oswaldo Cruz. 160 p. 2008.

3. CAVALCANTI. L. A. Efeitos de uma intervenção em escolares do ensino fundamental I, para a promoção de hábitos alimentares saudáveis. Dissertação de Mestrado. Universidade Católica de Brasília. 92p. 2009.

4. COELHO. R. et al. Excesso de peso e obesidade: Prevenção na escola. Acta Med Port. 21(4): 341-344. 2008.

5. COSTA. R. Artigo publicado pela revista ISTOÉ. n. $2140 ; 17 / 11 / 2010$.

6. DE LAVOR, A. Alimentação no Brasil: Um padrāo bem pouco saudável. RADIS Comunicação em Saúde. Rio de Janeiro. n. 56, abril, p.18-24, 2007.

7. EMBRAPA (ARROZ E FEIJÃO). http://enpaf.embrapa.br/ parperfeito/feijão/composição.htm. Acesso em 13/12/2010.

8. FELICE. M. M. et al. Análise do lanche escolar consumido por adolescentes. Saúde Revista. Piracicaba. 9 (22): 7 -14, 2007.

9. FLÁVIO. E. F. et al. Avaliação química e aceitação da merenda escolar de uma escola estadual de LavrasMG. Ciências Agrotécnicas, Lavras, v. 28, n. 4, p. 840-847, jul./ago., 2004.

10. JUNQUEIRA, E. O Triunfo do Hambúrguer. Revista Época, São Paulo, p. 54-60, 24 de abril de 2000. 
11. LEVY-COSTA, R.B., et al. Disponibilidade de alimentos no Brasil: distribuição e evolução (1974-2003). Revista Saúde Publica. 39(4):530-40. 2005.

12. OCHSENHOFER, K. et al. O papel da escola na formação da escolha alimentar: merenda escolar ou cantina? Nutrire: ver. Soc.Bras. Alim. Nutr. J.Brazilian Soc. Food. Nutr., São Paulo, SP,v.31,n.1,p.1-16,abr. 2006.

13. PIPITONE, M. A. P. et al. Atuação dos conselhos municipais de alimentaçáo escolar na gestáo do programa nacional de alimentação escolar. Revista de Nutriçáo, v.16, n.2, p.143-154, jun. 2003.

14. SALGADO, J. M. Ensine seu filho a comer corretamente. São Paulo. Disponível em:<http://www.multiplos.com.br/port/index.php?option=com_content \&task=view\&id=192\&Itemid=82 > Acesso em: 21 jan.2011. 2007.

15. SILVA. B. P. \& NEUTZLING. M. Freqüência de consumo de frutas e hortaliças em escolares adolescentes do município de Pelotas - RS. XVI Congresso de Iniciação Científica. Universidade Federal de Pelotas - RS. 2007.

16. SPINELLI, M. A. S. \& CANESQUI, A. M. Descentralização do programa de alimentação escolar em Cuiabá: 1993-1996. Revista de Nutriçáo. Campinas, 17(2): 151-165, abr/jun.2004.

17. STURION, G. L. e cols. Fatores condicionantes da adesão dos alunos ao Programa de Alimentação Escolar no Brasil. Revista de Nutriçáo. Campinas 18 (2): $167-$ 181, mar./abr., 2005.

18. TADDEI, J. A. Epidemiologia da Obesidade na Infância. In. Fisberg, M. Obesidade na Infância e na Adolescência. Fundação by K. São Paulo. 1995.

19. TADDEI, J. A. et al. Stunting wasting obesity trends in under five Brasilian children. The FASEB Journal, p. A342, 1998.

20. TORAL, N. et al. Comportamento alimentar de adolescentes em relação ao consumo de frutas e verduras. Revista de Nutriçáo. Campinas, 19(3): 331-340 maio/jun. 2006.

21. TORAL, N.; SLATER, B.; DA SILVA, M. V. Consumo alimentar e excesso de peso de adolescentes de Piracicaba, Revista de Nutrição. Campinas, 20(5): 449459, set./out., 2007.
22. TORRES, M. L. O compromisso social das escolas públicas com as novas tecnologias da comunicação e da informação. Revista Tecnologia Educacional, Ano XXXI, n. 161/162, Abr/03-Set/03.

23. UNICEF - Fundo das Naçóes para a Infância. Focusing Resources on Effective School Health: a FRESH Start to Improving the Quality and Equity of Education. Relatório final do Fórum Mundial de Educação. Senegal, 2000. Disponível em: <http:// unicef. org/lifeskills/files/FreshDocument.pdf.>. Acesso em: 20/01/2011.

24. VIUNISKI, N. Obesidade em adultos, um desafio pediátrico? Nutriçáo Brasil. Ano XIII n.74. p.9-10. set/ out. 2005.

25. ZANCUL, M. S. \& DUTRA DE OLIVEIRA, J. E. Considerações sobre Ações Atuais de Educação Alimentar e Nutricional para Adolescentes. Alim. Nutr., Araraquara, v.18, n.2, p. 223-227, jan/mar. 2007.

\section{Endereço para Correspondência:}

Maria de Fátima Alves de Oliveira - bio_alves@yahoo.com.br CENTRO UNIVERSITÁRIO MOACYR SREDER BASTOS

Rua Engenheiro Trindade, 229

Campo Grande - Rio de Janeiro - RJ

CEP: 23050-290 